Nonlinear Processes in Geophysics, 12, 461-469, 2005

SRef-ID: $1607-7946 / \mathrm{npg} / 2005-12-461$

European Geosciences Union

(C) 2005 Author(s). This work is licensed

under a Creative Commons License.

\title{
Streamflow dynamics at the Puget Sound, Washington: application of a surrogate data method
}

\author{
N. She and D. Basketfield \\ Seattle Public Utilities, City of Seattle, 700 5th Ave., Suite 4900, PO Box 34018, Seattle, WA 98124-4018, USA \\ Received: 8 December 2004 - Revised: 4 February 2005 - Accepted: 23 March 2005 - Published: 3 May 2005 \\ Part of Special Issue "Nonlinear deterministic dynamics in hydrologic systems: present activities and future challenges"
}

\begin{abstract}
Recent progress in nonlinear dynamic theory has inspired hydrologists to apply innovative nonlinear time series techniques to the analysis of streamflow data. However, regardless of the method employed to analyze streamflow data, the first step should be the identification of underlying dynamics using one or more methods that could distinguish between linear and nonlinear, deterministic and stochastic processes from data itself. In recent years a statistically rigorous framework to test whether or not the examined time series is generated by a Gaussian (linear) process undergoing a possibly nonlinear static transform is provided by the method of surrogate data. The surrogate data, generated to represent the null hypothesis, are compared to the original data under a nonlinear discriminating statistic in order to reject or approve the null hypothesis. In recognition of this tendency, the method of "surrogate data" is applied herein to determine the underlying linear stochastic or nonlinear deterministic nature of daily streamflow data observed from the central basin of Puget Sound, and as applicable, distinguish between the static or dynamic nonlinearity of the data in question.
\end{abstract}

\section{Introduction}

Irregular patterns and spikes are common in streamflow data, and for decades hydrologists have been trying to explain the cause of irregularity in the streamflow. Various methods covering a wide range of approaches, from detailed physically based computer models to complicated statistical analysis, has been used to characterize, analyze and forecast streamflow dynamics. For example, shot noise stochastic models were used to generate spikes of streamflow (Weiss, 1977; Murrone et al., 1997), while a number of studies (Tong, 1990; Kantz and Schreiber, 1997; Schreiber and Schmitz, 2000) have shown that a linear stochastic process undergo-

Correspondence to: N. She

(nian.she@seattle.gov) ing a possibly nonlinear static transform can also create very complex looking signals, suggesting that the apparent spikes and irregular patterns may be caused by either linear correlations or random input. Inspired by discoveries in the early 1980s of embedding theorems of time delay reconstruction (e.g. Packard et al., 1980; Takens, 1981) and of algorithms to calculate correlation dimensions of strange attractors (e.g. Grassberger and Procaccia, 1983a, b) numerous claims of low dimensional deterministic chaos in hydrologic time series data were reported (Nicolis and Nicolis,1984; Hense, 1987; Rodriguez-Iturbe et al., 1989; Jayawardena and Lai, 1994; Islam and Sivakumar, 2002; Sivakumar et al., 1999; Sivakumar, 2001; Sivakumar and Jayawardena, 2002; Regonda et al., 2004). But the results are not convincing. As discussed by Kantz and Schreiber (1997), Hegger et al. (1999), and Schreiber and Schmitz (2000), when applying algorithms developed to quantify deterministic lowdimensional chaos from field data, necessary procedures must be undertaken with care. These algorithms, especially the algorithms calculating correlation dimensions, only work under very strict conditions that data quality and quantity are sufficient to observe clear scaling regions. Further, these algorithms may incorrectly characterize non-chaotic and even linear stochastic process as low-dimensional chaos, particularly those of power law type linear correlations (e.g. Theiler, 1986; Osborne and Provenzale, 1989). Unfortunately, many early works in hydrology had not followed the necessary precautions when these algorithms were applied to hydrologic data. Consequently, the initial results of the studies have been followed by a wave of corrections and counterclaims (Pasternack, 1999; Schertzer et al., 2002).

Before building a model for the data (e.g. for prediction purposes), or applying algorithms for phase-space reconstruction (e.g. calculating correlation dimensions), it is advisable to check whether the data alone suggest this type of modeling or calculation. Why use advanced nonlinear prediction models if there is no evidence of nonlinear structure in the data? Or why put effort on detecting chaos from streamflow records at all if the pertaining data cannot be 
distinguished from linear stochastic process? The main objectives of the present study are to develop a statistically rigorous, foolproof framework, called "surrogate data test", to examine whether or not the streamflow time series is generated by a Gaussian (linear) process undergoing a possibly nonlinear static transform, and to apply this procedure to characterize twenty-three selected daily streamflows from the central basin of Puget Sound in the state of Washington.

\section{Surrogate data test}

The surrogate data test herein is referred as a statistical procedure that includes formulating a hypothesis, choosing a test statistic, specifying a probability of false rejection and generating surrogate data sets from original data set. The surrogate data test has not been used to investigate underlying hydrologic dynamics until recent years though the comparisons of surrogate data with original data were used in some hydrologic studies. Sivakumar et al. (1999) calculated correlation dimension from the original Singapore rainfall data to compare correlation dimension calculated from a surrogate of original data. No statistical test was really performed. Livina et al. (2003) compared seasonality of river flux increment series with the surrogate volatility series and found that the seasonal periodicity was almost diminished in surrogate volatility series, indicating that "periodic volatility" is a result of nonlinearity. Again, no test statistics were given. Moreover, the periodicity of surrogate volatility also disappeared when the noise level increased. This scheme indicates that the surrogate volatility does not always diminish the seasonal periodicity of the volatility series, but rather eliminates the nonlinear part of the process which is proportional to the noise level. Laio et al. (2004) applied deterministic versus stochastic (DVS) plots to the decay phases of daily discharges of three rivers in Italy and detected nonlinearity from the data. DVS was first introduced by Casdagli (1991). Though it is robust towards non-Gaussianity, it is difficult to distinguish between a nonlinear non-Gaussian system with a linear Gaussian system, since the possible nonlinearities tend to be dominated by the stochastic component. Furthermore, it is not a real statistical test "since no test statistics are produced which allows a unequivocal acceptance or rejection of the null hypothesis of linearity" (Laio et al., 2004). Laio et al. (2004) also showed that a surrogate data set generated from a linear decay system with non-Gaussian shot noise (see Eq. 3 below) appeared significantly different than an original data set and tested for reversibility using a simple third order statistic. The authors concluded that when applying a surrogate data test, it is only valid to test a linear Gaussian stochastic process. It is apparent that the process generated from Eq. (3) is irreversible, but that does not mean that the process is not linear, so choosing a statistic in the surrogate data test is the key. Indeed, by choosing appropriate robust nonlinear statistics, the surrogate data test may be justified when the noise deviates from a Gaussian process (Kantz and Schreiber, 1997; Schreiber and Schmitz, 2000).
We will show herein that the null hypothesis of linearity can not be rejected by our surrogate data test from Eq. (3), while the linearity is rejected correctly when we apply our surrogate data test to a nonlinear system in Eq. (4). This indicates, when an appropriate statistic is chosen, surrogate data test is not only sensitive, but also robust and has larger statistical power. The surrogate data test, in any case, is a useful tool for data driven hydrologic analysis.

If the null hypothesis, that the underlying hydrologic process is a linear (possibly Gaussian) stochastic process, can not be rejected, then either it is due to the finite power of the test (we expect that the null hypothesis will be rejected only with probability $\beta<1$, where $\beta$ is defined as the probability that the null hypothesis is rejected when it is indeed false) or the hypothesis actually describes the data properly. In the latter case, one can apply ARMA-type models to the hydrologic data under investigation. If the null hypothesis is rejected: (1) the rejection could have happened by chance with a probability of $\alpha,(2)$ the data may be nonstationary, (3) the measurement function could depend on more than one measurement and is noninvertible; or finally, (4) the process is nonlinear. In all cases but the last one the rejection is not justified. One way to justify the rejection is to use other methods such as DVS plot to see whether or not the minimum prediction error occurs at smaller neighborhood size (Casdagli, 1991), or to compare the spectrum of increment series with surrogate volatility series (Linvina et al., 2003). After the rejection is justified, one may investigate other properties of the data or calculate additional invariants such as correlation or fractal dimensions.

The rest of this section is organized as follows: first we briefly introduce the procedures in the surrogate data test. Then we choose nonlinear statistics to test linear and nonlinear decay systems with Poisson distributed shot noise (see Eqs. 3 and 4). Finally, we apply DVS plot to the nonlinear decay system to justify that the rejection of the null hypothesis is indeed due to existence of nonlinear properties.

The first step in the surrogate data test is to formulate a null hypothesis. In our case, the null hypothesis is that the streamflow data is sampled from a Gaussian linear stochastic process, i.e.

$q_{n}=\sum_{i=1}^{p} a_{i} q_{n-i}+\sum_{j=1}^{q} b_{j} \eta_{n-j}$,

where $q_{n}$ is the subject time series, $\eta_{n}$ is an independent Gaussian random variable with zero mean and unit variance, and $a_{i}$ and $b_{i}$ are coefficients (Diggle, 1989).

Note that it is not our intention to merely test our hypothesis against one particular linear stochastic process, e.g. to test for the correct choice of a model of order $p$ and $q$ with specified $a_{i}$ and $b_{i}$. Rather, we wish to test against a whole class of processes defined by Eq. (1) with unknown values $p, q, a_{i}$ and $b_{i}$. Moreover, we want to test the more general hypothesis that includes the possibility that the data were observed 

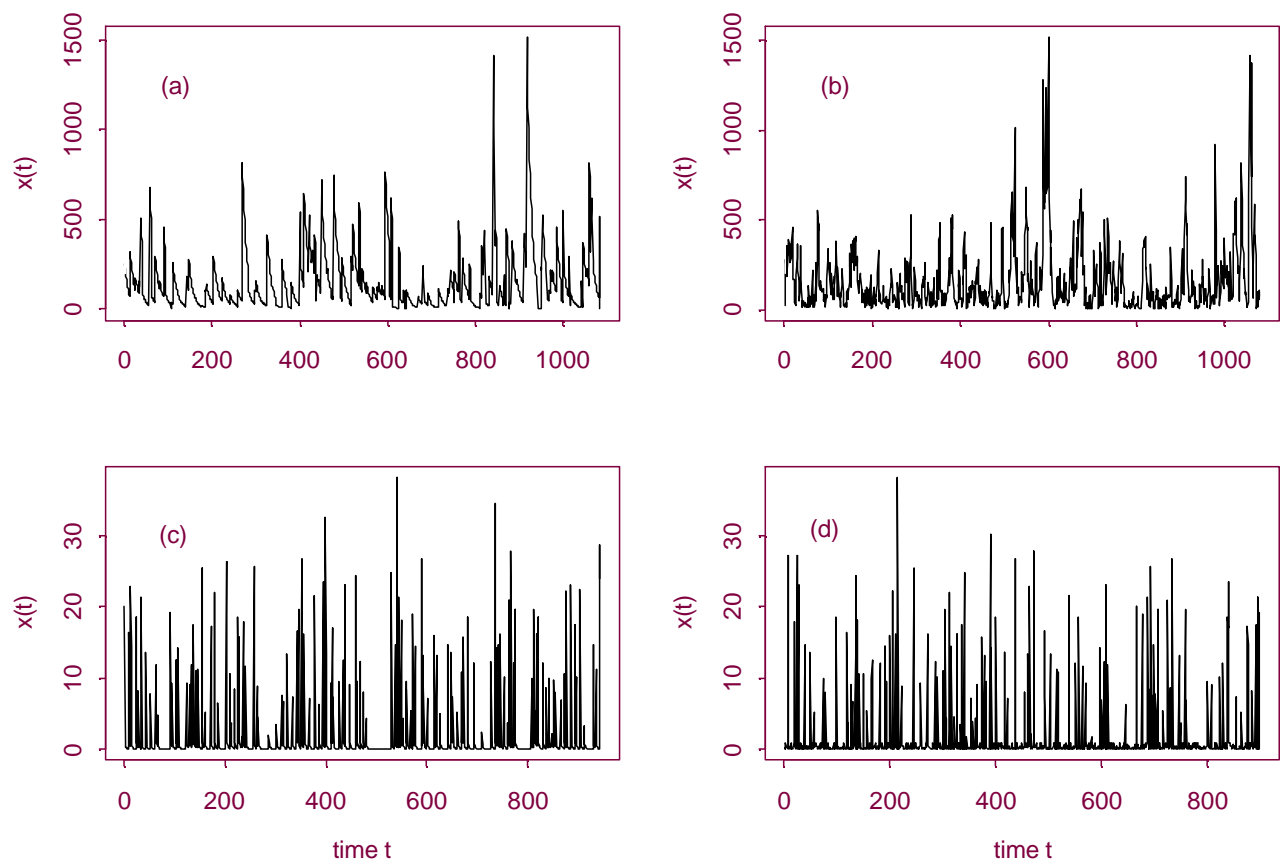

Fig. 1. (a) Samples from a linear shot noise process defined in Eq. (3)and (b) a corresponding surrogate series. (c) Samples from a nonlinear shot noise process defined in Eq. (4) and (d) a corresponding surrogate series.

through the instantaneous, invertible and static, but possibly nonlinear functions given by

$Q_{n}=h\left(x_{n}\right), \quad x_{n}=\sum_{i=1}^{p} a_{i} q_{n-i}+\sum_{j=1}^{q} b_{j} \eta_{n-j}$

where $h$ is called measurement function, which may be nonlinear and invertible. So, the process given by Eq. (2) is considered as a linear stochastic process defined in Eq. (1), but transformed by a possible static nonlinear measurement function $h$ (Kantz and Schreiber, 1997; Schreiber and Schmitz, 2000).

Next, we need to choose a test statistic to actually perform the test. Conventional statistics, like Student's t or Chisquare in basic statistical analysis, result in a number that will lead us to either reject or accept the null hypothesis. From a statistical point of view, we hope the statistic chosen for the test is robust, i.e. when the distribution of samples depart from assumed underlying distribution, the statistic still has test power. In order to test the hypothesis that the data is generated from the more general process defined in Eq. (2), a nonlinear test statistic $\lambda$ must be computed from the data. This test statistic may be a prediction error or a dimension, but in any case it must not depend on the parameters in Eq. (2), and also be robust and powerful enough to distinguish the difference between static and dynamic nonlinearity.

The final step is to generate surrogate data sets. Recall that a linear stochastic process can be fully described by its first and second moments, such as its mean, variance and autocorrelation function, and also note that the unknown parameters in our null hypothesis reflect specific properties of interest of the data. For example, the unknown autocorrelation coefficients under a linear stochastic null hypothesis are reflected in the autocorrelation function of the data.

Now we apply the procedures described above to two examples: one is a linear shot noise process, and the other is a nonlinear shot noise process. Both processes are, respectively, given by

$$
\begin{aligned}
& \frac{d x}{d t}=-x(t)+N_{p}(t) \\
& \frac{d x}{d t}=-x^{2}(t)+N_{p}(t),
\end{aligned}
$$

where $N_{p}(t)$ is the random driving process in the form of a white Poisson noise and is defined by a sequence of pulses at random times $\tau_{i}$, each pulse having an independent random amplitude $h_{i}$, i.e.

$N_{p}(t)=\sum_{i}^{h_{i}} \delta\left(t-\tau_{i}\right)$,

where $\delta(\cdot)$ is the Dirac delta function and $\left\{\tau_{i}\right\}$ come from a Poisson distribution. Figure 1 shows the samples and their corresponding surrogate series generated from Eqs. (3) and (4).

Evidently, both samples are very different from their corresponding surrogate series. To test the linearity versus nonlinearity, we choose zeroth-order nonlinear prediction error as a discriminating statistic. It was shown that zeroth-order nonlinear prediction error is a robust and powerful statistic (Pikovsky, 1986; Kennel and Isabelle, 1992; Theiler and Prichard, 1996; Kantz and Schreiber, 1997). 

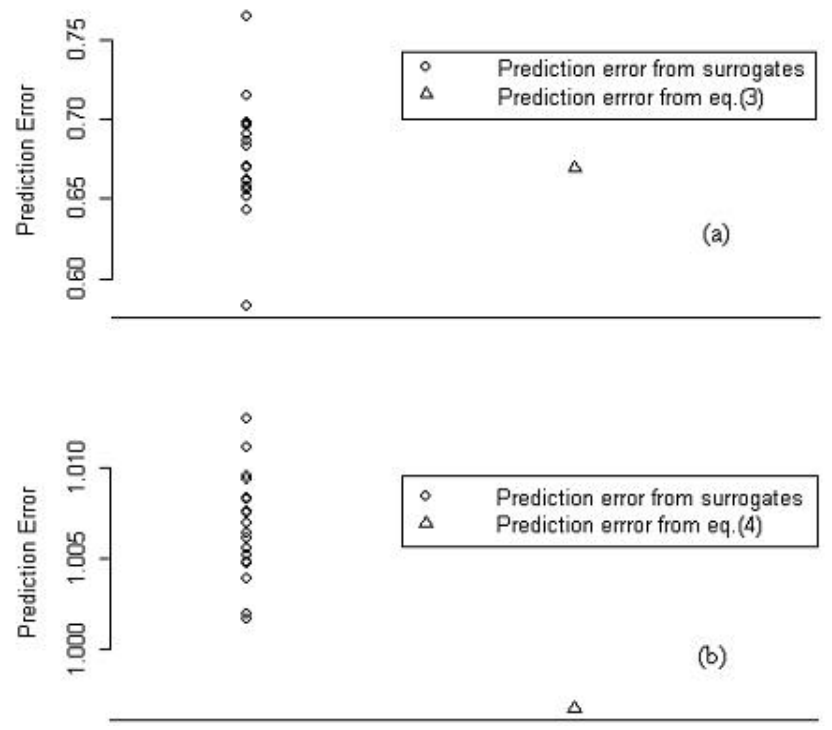

Fig. 2. (a) Prediction errors for Eq. (3) and 19 corresponding surrogates, (b) Prediction errors for Eq. (4) and 19 corresponding surrogates,. Prediction errors are estimated using embedding dimension $m=1$ and time delay $\tau=1$.

The surrogate data test is set up in such a way that the null hypothesis may be rejected when the prediction error is smaller for the data than for all of the nineteen surrogates. Figure 2 shows the plots of the prediction errors. To distinguish prediction errors between surrogates and original data we plot the prediction errors from surrogates on the left and the prediction errors from the original data on the right. As we can see from Fig. 2, the prediction error of the linear process is not significantly smaller than that of all nineteen surrogates, that is, the predictability is not significantly reduced by destroying possible nonlinear structure. The prediction error of the nonlinear process, however, is the smallest one among all nineteen surrogates. This shows that the test works correctly, even though the random errors are generated from a non-Gaussian process.

Further, we apply DVS plot to investigate whether or not the rejection is due to nonlinearity. Figure 3 shows clearly that the minimum prediction error occurs at medium neighborhood size, which is a signature of so called "weak nonlinearity" when the nonlinear structure in the system is weak and the noise level is moderate (Casdagli, 1991).

\section{Characterization of streamflow in central basin of Puget Sound}

Puget Sound is a $35000 \mathrm{~km}^{2}$ region of western Washington located at the northwest corner of the United States. Cupped between the jagged Olympic Mountains to the west and the volcanic peaks of the Cascade Range to the east with majestic Mount Rainier standing at $4392 \mathrm{~m}$, the Puget Sound basin has among the most diverse hydrologic conditions of any region in the United States, varying from arid conditions in

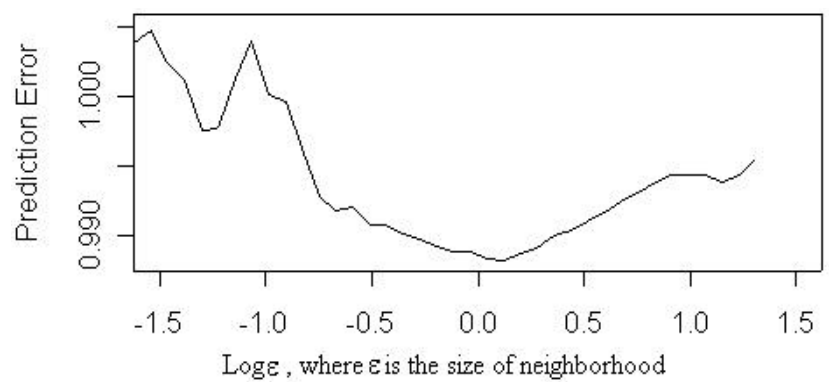

Fig. 3. DVS plot for a nonlinear shot noise process defined in Eq. (4). 1000 samples are generated from Eq. (4). Prediction errors are estimated using embedding dmension $m=1$ and time delay $\tau=1$.

the shadows of the Olympic and Cascade Mountains to very wet rainforest along the Pacific coast. In the coastal area and Cascade Mountains, the maximum precipitation occurs during the winter months, while in the eastern basins, with more steppe and continental climates, the maximum precipitation occurs in the early summer. On average, the region receives about $1000 \mathrm{~mm}$ of precipitation annually. Much of the annual precipitation falls between November and April as rain and with snow at high altitudes.

Streamflows in the Puget Sound basins are largely influenced by seasonal snowpack melt off over spring and early summer. Runoff from rainstorms and groundwater discharge (in the form of springs or seeps) from shallow aquifers also influence the amount and form of water that drives streamflow in its rivers and streams. To better manage water resources in the Puget Sound basin, it is essential to have a clear understanding of the characteristics of streamflow hydrology. Unlike the conventional characterization of streamflow using either a physically based model or a statistically based model (such as regression analysis or ARMA), we use nonlinear dynamics tools developed for time series analysis to investigate the characteristics of the streamflow, such as dimensionality, predictability, periodicity, deterministic nonlinearity and probability. The theoretical foundation of our characterization is borrowed from Taken's time delay embedding theorem of phase-space reconstruction and surrogate data test described in the previous section.

Twenty-three daily streamflow time series in central basin of Puget Sound are chosen for characterization. These streamflows represent three typical watersheds in Puget Sound basin: rainfall-driven streams, snowmelt-driven streams, and hybrid (mixed rainfall- and snowmelt-driven) streams. The drainage areas range from 12.2 to $1385.6 \mathrm{~km}^{2}$; average daily flows over the study time period (from 19.5 years to 74 years) range from 0.62 to $112.2 \mathrm{~m}^{3} / \mathrm{s}$; the elevations range from 11 to $564 \mathrm{~m}$ a.s.l.; and the length of the time series range from 20 to 74 continuous years. All streamflow data are measured and processed by the United States Geologic Survey (USGS) and can be found at the website: http://waterdata.usgs.gov/nwis/sw. Table 1 lists some of the important physical characteristics of these twenty-three subbasins and statistics of the observed streamflows. 
Table 1. Physical characteristics of 23 streamflows in central Basin of Puget Sound.

\begin{tabular}{|c|c|c|c|c|c|}
\hline Station ID & Station name & Drainage area $\left(\mathrm{km}^{3}\right)$ & Datum a.s.l. (m) & Mean flow $\left(\mathrm{m}^{3} / \mathrm{s}\right)$ & Length of data \\
\hline 12121600 & Issaquah Creek near Mouth Near Issaquah & 146.6 & 11 & 3.76 & $10 / 1 / 1963-9 / 30 / 2002$ \\
\hline 12167000 & NF Stillaguamish River near Arlington & 678.6 & 27 & 53.61 & 8/1/1928-9/30/2002 \\
\hline 12060500 & South Fork Skokomish River near Union & 197.6 & 32 & 20.96 & $8 / 1 / 1931-9 / 30 / 1985$ \\
\hline 12122500 & Bear Creek near Redmond & 36.0 & 34 & 0.62 & 5/16/1979-9/30/1996 \\
\hline 12134500 & Skykomish River near Gold Bar & 1385.6 & 64 & 112.20 & $10 / 1 / 1928-9 / 30 / 2002$ \\
\hline 12054000 & Duckabush River near Brinnon & 172.2 & 74 & 11.78 & $7 / 1 / 1938-9 / 30 / 2002$ \\
\hline 12108500 & Newaukum Creek near Black Diamond & 71.0 & 94 & 1.67 & $10 / 1 / / 1952-9 / 30 / 2002$ \\
\hline 12161000 & SF Stillaguamish River near Granite Falls & 308.2 & 94 & 30.29 & 8/1/1928-9/30/2002 \\
\hline 12079000 & Deschutes River near Rainier & 232.6 & 106 & 7.55 & 6/1/1949-9/30/1976 \\
\hline 12056500 & NF Skokomish R BL Staircase RPDS NR Hoodsport & 148.1 & 232 & 14.41 & $8 / 1 / 1924-9 / 30 / 2002$ \\
\hline 12141300 & Middle Fork Snoqualmie River near Tanner & 398.9 & 238 & 35.02 & 2/1/1961-9/30/2002 \\
\hline 12117000 & Taylor Creek near Selleck & 44.5 & 287 & 2.75 & $8 / 1 / 1956-9 / 30 / 2002$ \\
\hline 12142000 & NF Snoqualmie River near Snoqualmie Falls & 165.8 & 344 & 14.32 & 3/1/1961-9/30/2002 \\
\hline 12094000 & Carbon River near Fairfax & 204.4 & 366 & 12.14 & $4 / 1 / 1929-5 / 31 / 1978$ \\
\hline 12083000 & Mineral Creek near Mineral & 194.8 & 408 & 10.25 & 6/1/1942-9/30/2002 \\
\hline 12143400 & SF Snoqualmie River AB Alice Creek near Garcia & 107.7 & 438 & 8.55 & 10/1/1960-9/30/2002 \\
\hline 12082500 & Nisqually River near National & 344.5 & 442 & 21.87 & 6/1/1942-9/30/2002 \\
\hline 12115000 & Cedar River near Cedar Falls & 105.4 & 475 & 7.34 & $10 / 1 / 1945-9 / 30 / 2002$ \\
\hline 12115500 & Rex River near Cedar Falls & 34.7 & 488 & 2.87 & $10 / 1 / 1945-9 / 30 / 2002$ \\
\hline 12092000 & Puyallup River near Electron & 7.3 & 497 & 14.95 & 1/1/1958-9/30/2002 \\
\hline 12097500 & Greenwater River at Greenwater & 190.4 & 526 & 5.99 & 5/1/1929-9/30/1977 \\
\hline 12147600 & South Fork Tolt River near Index & 13.8 & 564 & 1.56 & $8 / 1 / 1928-12 / 27 / 1980$ \\
\hline 12115700 & Boulder Creek near Cedar Falls & 12.0 & & 0.69 & 3/1/1983-9/30/2002 \\
\hline
\end{tabular}

Table 2. Power spectrum analysis of 23 streamflows in central basin of Puget Sound.

\begin{tabular}{|c|c|c|c|c|}
\hline Station ID & Station name & Dominate periodicity & Harmonics & Sub-harmonics \\
\hline 12054000 & Duckabush River near Brinnon & 6 months & & 12 months \\
\hline 12056500 & NF Skokomish R BL Staircase RPDS NR Hoodsport & 12 months & 6 months & \\
\hline 12060500 & South Fork Skokomish River near Union & 12 months & 6 months & \\
\hline 12079000 & Deschutes River near Rainier & 12 months & 6 months & \\
\hline 12082500 & Nisqually River near National & 6 months & & 12 and 82 months \\
\hline 12083000 & Mineral Creek near Mineral & 12 months & 6 months & \\
\hline 12092000 & Puyallup River near Electron & 6 months & & 12,22 and 90 months \\
\hline 12094000 & Carbon River near Fairfax & 6 months & & 12 and 54 months \\
\hline 12097500 & Greenwater River at Greenwater & 12 months & 3,4 and 6 months & 59 and 197 months \\
\hline 12108500 & Newaukum Creek near Black Diamond & 12 months & 6 months & 87 months \\
\hline 12115000 & Cedar River near Cedar Falls & 12 months & 6 months & \\
\hline 12115500 & Rex River near Cedar Falls & 12 months & 6 months & \\
\hline 12115700 & Boulder Creek near Cedar Falls & 12 months & 6 months & 40 months \\
\hline 12117000 & Taylor Creek near Selleck & 12 months & 6 months & 23 and 93 months \\
\hline 12121600 & Issaquah Creek Near Mouth near Issaquah & 12 months & 6 months & 25 and 95 months \\
\hline 12122500 & Bear Creek near Redmond & 12 months & & 30 months \\
\hline 12134500 & Skykomish River near Gold Bar & 6 months & & 12 months \\
\hline 12141300 & Middle Fork Snoqualmie River near Tanner & 6 months & & 12,19 and 84 months \\
\hline 12142000 & NF Snoqualmie River near Snoqualmie Falls & 6 months & & 12,25 and 84 months \\
\hline 12143400 & SF Snoqualmie River AB Alice Creek near Garcia & 6 months & & 12,20 and 72 months \\
\hline 12147600 & South Fork Tolt River near Index & 6 months & & 12 months \\
\hline 12161000 & SF Stillaguamish River near Granite Falls & 12 months & 6 months & \\
\hline 12167000 & NF Stillaguamish River near Arlington & 12 months & 6 months & \\
\hline
\end{tabular}



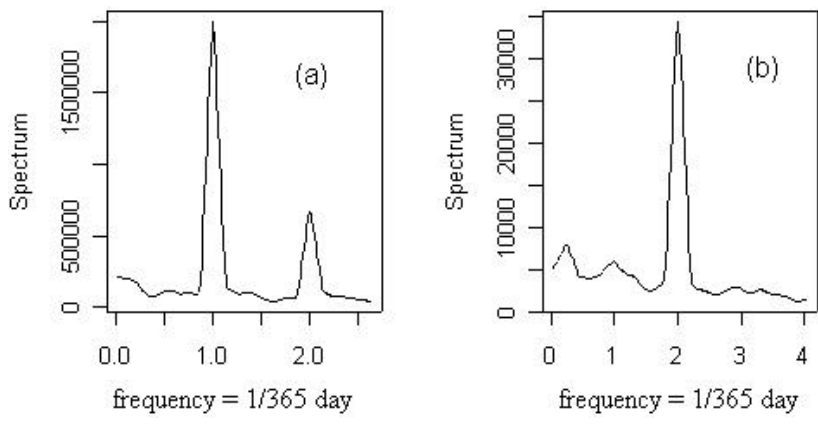

Fig. 4. Power spectrum analysis for streamfroms (a) at USGS 12167000 and (b) at USGS 12094000. (a) shows harmonic periodicity; (b) shows subharmonic periodicity.

Different streams with different drainage areas at different elevations respond differently to the winter inflow of moisture to the region. Streams at low elevations (e.g. USGS 12121600) tend to respond quickly and directly to the precipitation that falls on the basin, since the basin temperatures are typically above freezing level, and all the precipitation falls as rain. Streams at moderate elevations (e.g. USGS12115000) have a transient snow zone, where precipitation frequently falls as snow but then melts a few days or weeks later in a cycle that is typically repeated many times in the winter. The transient snow zone can cause flooding if heavy rain and warm temperatures occur at the same time when snow has already accumulated. Typically streams of this type show a dual peaked hydrograph: one during the winter, another during spring or early summer. Figure 4a shows the power spectrum of streamflow at a moderate elevation. Clearly, two periodicities occur at six-month and one-year periods. It can be seen that the annual periodicity is stronger than the six-month periodicity. This is referred to as harmonic cycles in time series analysis. However, Fig. 4b shows a different scenario, i.e. the six-month periodicity is stronger than the annual and long-term (54-month) periodicity. This is referred to as sub-harmonic in time series analysis, which is usually the evidence of existing long term cycles.

Table 2 shows the results of power spectral analysis from which the periodicity of the streamflow time series are identified clearly. Moreover, the complexity of the data is shown through the harmonics and sub-harmonics of frequencies and periodicity.

The deviation of hydrographs from typical dual peaks in some streamflows (most in moderate elevations) may be the effect of El Niño Southern Oscillation (ENSO) phenomenon to transient snow zones. Numerous researchers (Koch et al., 1991; Redmond and Koch, 1991; Chiew et al., 1998) have shown that the snowpack in the Pacific Northwest regions is evidently affected by ENSO, such as Southern Oscillation Index (SOI), sea surface temperatures (SST) and Pacific Decadal Oscillation (PDO). These oscillators usually have 3 to 10 year cycles. An El Niño event can lead to a drier and warmer than normal winter, while a La Niña event can
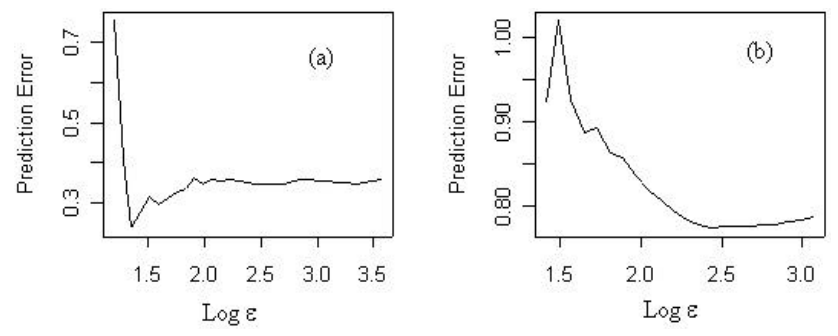

Fig. 5. DVS plots for two daily streamflow discharges in central basin of Puget Sound (a) USGS 12097500, (b) USGS 12147600. Time delay and embedding dimensions are the same as in Table 3, where $\varepsilon$ is the size of neighborhood.

lead to a wetter and cooler than normal winter. The variability observed in the streamflows, both from year to year and within the year, is related to these large-scale features in the ocean and atmosphere. Correlations between streamflows and ENSO have been found in many streams in Pacific Northwest (Peter et al., 2002; Piechota and Dracup, 1999). The streamflow records reflect the interactions between seasonality and long-term cycles of climate.

From Table 2, it is clear that either a six-month or a twelve-month periodicity dominates the streamflow dynamics. However, sub-harmonic frequencies are present in most data sets at moderate elevations. This implies that, not only annual and semi-annual cycles, but also long-term cycles play important roles in these streamflow processes. The interaction of a dominant frequency with harmonic and subharmonic frequencies may create various complex behaviors of the streamflow from linear stochastic process to deterministic chaos, or something in between such as quasiperiodicity or tori. Our next task, therefore, is to test these complexities using a surrogate data test.

To conduct the surrogate data test, we need to choose an appropriate nonlinear statistic. As we demonstrated in the previous section, the zeroth-order prediction error is a robust and powerful nonlinear statistic. Therefore, we use this statistic to test the twenty-three streamflows versus their corresponding surrogates. If the null hypothesis were rejected, we use DVS plot for further investigation. The surrogate data test and the DVS plot are performed using the software package TISEAN (Hegger et al., 1999).

The results of the surrogate data test for the twenty-three streamflows in the central basin of Puget Sound are presented in Table 3.

Zeroth-order prediction error is chosen as the test statistic. The time delay and embedding dimensions associated with prediction errors are the key elements in the algorithm of the zeorth-order prediction. If the time delay $\tau$ is taken too small, there is almost no difference between the different components of the embedding vectors, such that all points are concentrated around the diagonal. On the other hand, if it is taken too large, the different coordinates may be almost uncorrelated, such that the reconstructed attractor becomes very 
Table 3. Surrogate data tests of 23 streamflow in central basin of Puget Sound.

\begin{tabular}{llcccc}
\hline Station ID & Station name & $\begin{array}{c}\text { Embedding } \\
\text { dimension }\end{array}$ & Delays & Test & Period \\
\hline 12054000 & Duckabush River near Brinnon & 7 & 52 & Reject & $7 / 1 / 1938-9 / 30 / 2002$ \\
12056500 & NF Skokomish R BL Staircase RPDS NR Hoodsport & 7 & 62 & Reject & $8 / 1 / 1924-9 / 30 / 2002$ \\
12060500 & South Fork Skokomish River near Union & 7 & 59 & Reject & $8 / 1 / 1931-9 / 30 / 1985$ \\
12079000 & Deschutes River near Rainier & 12 & 71 & Not Reject & $6 / 1 / 1949-9 / 30 / 1976$ \\
12082500 & Nisqually River near National & 6 & 64 & Not Reject & $6 / 1 / 1942-9 / 30 / 2002$ \\
12083000 & Mineral Creek near Mineral & 8 & 82 & Not Reject & $6 / 1 / 1942-9 / 30 / 2002$ \\
12092000 & Puyallup River near Electron & 8 & 40 & Reject & $1 / 1 / 1958-9 / 30 / 2002$ \\
12094000 & Carbon River near Fairfax & 13 & 42 & Not Reject & $4 / 1 / 1929-5 / 31 / 1978$ \\
12097500 & Greenwater River at Greenwater & 5 & 71 & Reject & $5 / 1 / 1929-9 / 30 / 1977$ \\
12108500 & Newaukum Creek near Black Diamond & 13 & 42 & Not Reject & $10 / 1 / 1952-9 / 30 / 2002$ \\
12115000 & Cedar River near Cedar Falls & 6 & 60 & Reject & $10 / 1 / 1945-9 / 30 / 2002$ \\
12115500 & Rex River near Cedar Falls & 8 & 53 & Not Reject & $10 / 1 / 1945-9 / 30 / 2002$ \\
12115700 & Boulder Creek near Cedar Falls & 13 & 26 & Reject & $3 / 1 / 1983-9 / 30 / 2002$ \\
12117000 & Taylor Creek near Selleck & 9 & 85 & Reject & $8 / 1 / 1956-9 / 30 / 2002$ \\
12121600 & Issaquah Creek near Mouth Near Issaquah & 7 & 58 & Reject & $10 / 1 / 1963-9 / 30 / 2002$ \\
12122500 & Bear Creek near Redmond & 9 & 20 & Not Reject & $5 / 16 / 1979-9 / 30 / 1996$ \\
12134500 & Skykomish River near Gold Bar & 8 & 52 & Not Reject & $10 / 1 / 1928-9 / 30 / 2002$ \\
12141300 & Middle Fork Snoqualmie River near Tanner & 16 & 43 & Not Reject & $2 / 1 / 1961-9 / 30 / 2002$ \\
12142000 & NF Snoqualmie River near Snoqualmie Falls & 8 & 51 & Not Reject & $3 / 1 / 1961-9 / 30 / 2002$ \\
12143400 & SF Snoqualmie River AB Alice Creek near Garcia & 11 & 52 & Reject & $10 / 1 / 1960-9 / 30 / 2002$ \\
12147600 & South Fork Tolt River near Index & 13 & 15 & Reject & $8 / 1 / 1928-12 / 27 / 1980$ \\
12161000 & SF Stillaguamish River near Granite Falls & 14 & 45 & Reject & $8 / 1 / 1928-9 / 30 / 2002$ \\
12167000 & NF Stillaguamish River near Arlington & 10 & 60 & Reject & $8 / 1 / 1928-9 / 30 / 2002$ \\
\hline
\end{tabular}

complicated and the original structure of the attractor is lost. The choice of time delay $\tau$ is here based on the so-called mutual information (Frazer and Swinney, 1986), which can be considered as a nonlinear analogue to linear correlation and is more adequate than an autocorrelation function when nonlinear dependencies are present. A possible rule to choose an appropriate time delay $\tau$ is to use the first minimum of the time delayed mutual information. Thus, the components of the embedding vectors can be considered independent at least with this lag.

It can be seen that, for most streamflows in Table 3 the time delays are quite large, somewhere from 15 days to 85 days. This may be due to the fact that most streamflows in this study are either snowmelt-driven or hybrid (mixed rainfalland snowmelt-driven). These sub-basins receive most precipitation from November to April. During these six months, a cycle of snow falls and melts off (described earlier) occurs frequently. The snowpack at transient zones are typically completely melted off in early June. During summer months (from July to September), these sub-basins receive very little precipitation. Therefore, streamflows in these subbasins may have long-term persistence. Also, soil moisture and permeability, forest canopies, and topographies of subbasins may be factors associated with the time delay. While no extensive investigation on the effects of time delay has been conducted on these streamflows, the study by Regonda et al. (2004) in a nearby area, Stillaguamish River, found a similar long time lag using the first zero autocorralation function. The long time showed the additional complexity inherent in the subject streamflow.

The embedding dimensions are determined using false nearest neighbors proposed by Kennel et al. (1992). The range of embedding dimensions for these streamflows are from 5 to 16 . Note that the embedding dimension thus obtained is not necessarily equal to the dimension of the entire hydrologic system. By Taken's theorem, the original system is topologically equivalent to embedded system as long as the embedding dimension $m$ is as twice as large than the dimension of the original system $n$. Therefore, the embedding dimension is an upper bound of the real dimension of the system.

Using the surrogate data test, we find that about $57 \%$ of the selected streamflow data sets were unlikely to be generated by linear stochastic processes. So, we further investigate, using DVS plot, whether or not the rejections were due to nonlinearity. Figure 5 shows plots of the prediction errors as a function of log neighborhood size from two streamflows measured at USGS 12097500 (Greenwater River at Greenwater, WA) and USGS 12147600 (South Fork Tolt River Near Index, WA), respectively. From Fig. 5a, one can see that the minimum prediction error occurs at small neighborhood size, which is a clear indication of nonlinearity. However, in Fig. $5 b$, the minimum is not seen at small neighborhood size, but somewhere in the moderate neighborhood size. This shows that determinism is weaker, presumably due to a much higher noise level. Most DVS plots for streamflows are 
similar to Fig. 5b, which indicates that linear stochastic processes and high dimensional deterministic processes make no difference in short-term prediction. For the rest of the $43 \%$ streamflows that did not pass the surrogate data test, it appears that the data were generated from stochastic processes.

\section{Conclusion and closing remarks}

In this paper we introduced a statistically rigorous framework, called surrogate data test, to examine whether or not the streamflow under investigation is generated by a Gaussian (linear) process undergoing a possibly nonlinear static transform. The surrogate data, generated to represent the null hypothesis, are compared to the original data under a nonlinear discriminating statistic in order to reject or accept the null hypothesis. The negative result can mean several things. The statistics chosen may just not have any power to detect the kind of nonlinearity present. Alternatively, the underlying process may be linear and the null hypothesis true. It could also be, and this seems the most likely option after all we know about the equations governing hydrologic process, which is nonlinear but the single time series at this sampling covers such a poor fraction of the rich dynamics that it must appear linear stochastic to the analysis. When the null hypothesis is rejected, we have to keep in mind that the rejection has to be justified because it may depend on the applied nonlinear method and the choice of the nonlinear statistics (e.g. a linear process with Poisson distributed shot noise was incorrectly rejected by using a simple third order statistic, but was accepted by using prediction errors of false nearest neighbors, see Sect. 2), or the measurement function could depend on more than one measurement. Hence, we suggest to use more than one method such as DVS plot or to compare the spectrum of increment series with surrogate volatility series to confirm the result. We have to also keep in mind that a rejection after the justification only indicates nonlinearity, not necessarily low dimensional deterministic chaos.

Streamflow is a complex hydrologic process. Even the knowledge that certain components of a hydrologic system may exhibit nonlinear behavior does not necessarily lead to the conclusion that a specific output of the system (e.g. streamflow) is consequently nonlinear, or that this nonlinearity will be proven evident in streamflow dynamics. Instead of pre-supposing the underlying dynamics, we use surrogate data test to represent the dynamics in an 'inverse' manner. We have shown in Sect. 2 that surrogate data test is a powerful statistical tool that is capable of distinguishing nonlinear dynamics from linear stochastic processes, even if the noise is generated from non-Gaussian sources. This has significant implications in hydrology because in most cases streamflow records are obtained through a measurement function and their statistical distribution are usually unknown.

Unlike conventional characterization of streamflow, we introduced concepts fairly new and recent to hydrologists, such as embedding dimension, time lag and prediction errors. These concepts have significant application to hydrol- ogy. Embedding dimension and time lag illustrate the complexity of the system. Prediction errors show certain structure of the dynamic system. For example, embedding dimension $\mathrm{m}$ gives an upper bound of the original dynamic system. Moreover, this bound is determined from measured data rather than through a prejudiced model subjectively selected by investigators. We applied these concepts together with surrogate data test to characterize twenty-three streamflows in the central basin of Puget Sound. As we have shown in Sect. 3 that the complexity of these streamflows are characterized by the length of time delays, the degrees of embedding dimensions, harmonic and sub-harmonic periods in streamflow time series, and the linear stochastic and nonlinear dynamic processes presented in the streamflows.

In the review of searching for lower dimensional chaos from field data, we recommend researchers to use surrogate data test as the first cut of screening. If the nonlinearity does not exist in the data, why not bother to calculate invariants such as fractal and correlation dimensions to make a possible false claim?

Acknowledgements. The authors would like to thank B. Sivakumar for his comments on an earlier version of the manuscript.

Edited by: B. Sivakumar

Reviewed by: two referees

\section{References}

Casdagli, M.: Chaos and deterministic versus stochastic nonlinear modeling, J. Roy. Stat. Soc. B, 54, 303-324, 1991.

Chiew, F. H. S., Piechota, T. C., Dracup, J. A., and McMahon, T. A.: El Niño/Southern Oscillation and Australian rainfall, streamflow and drought: links and potential for forecasting, J. Hydrol., 204, 138-149, 1998.

Diggle, P. J.: Time Series A Biostatistical Introduction, Oxford University Press, Oxford, 1989.

Frazer, A. M. and Swinney, H. L.: Independent coordinates in strange attractors from mutual information, Phys. Rev. (A), 33, 1134-1140, 1986.

Grassberger, P. and Procaccia, I.: Characterization of strange attractors, Phys. Rev. Lett., 50, 346-349, 1983a.

Grassberger, P. and Procaccia, I.: Estimation of the Kolmogorov entropy from a chaotic signal, Phys. Rev. (A), 28, 2591-2593, $1983 b$.

Hegger, R., Kantz, H., and Schreiber, T.: Practical implementation of nonlinear time series methods: The TISEAN package, CHAOS, 9, 413-435, 1999.

Hense, A.: On the possible existence of a strange attractor for the southern oscillation, Beitr. Phys. Atmos., 60, 34-47, 1987.

Islam, M. N. and Sivakumar, B.: Characterization and prediction of runoff dynamics: A nonlinear dynamical view, Adv. Wat. Resour., 25, 179-190, 2002.

Jayawardena, A. W. and Lai, F.: Analysis and prediction of chaos in rainfall and stream flow time series, J. Hydro., 153, 23-52, 1994.

Kantz, H. and Schreiber, T.: Nonlinear Time Series Analysis, Cambridge University Press, Cambridge, 1997.

Kennel, M. B., Brown, R., and Abarbanel, H. D. I.: Determining embedding dimension for phase-space reconstruction using a geometrical construction, Phys. Rev. (A), 45, 3403-3411, 1992. 
Kennel, M. B. and Isabelle, S.: Method to distinguish possible chaos from colored noise and to determine embedding parameters, Phys. Rev. (A), 46, 3111, 1992.

Koch, R. W., Buzzard, C. F., and Johnson, D. M.: Variation of snow water equivalent and streamflow in relation to the El Niño/ Southern Oscillation, Proceedings, Western Snow Conference, 59, 37 48, 1991.

Laio F., Porporato, A., Ridolfi, L., and Rodriguez-Iturbe, I.: Mean first passage times of processes driven by white shot noise, Phys. Rev. (E), 63, 036105, 1-8, 2001.

Laio F., Porporato, A., Ridolfi, L., and Tamea, S.: Detecting nonlinearity in time series driven by non-Gaussian noise: the case of river flows, Nonlin. Proc. Geophys, 11, 463-470, 2004, SRef-ID: 1607-7946/npg/2004-11-463.

Linvina, V. N., Ashekenazy, Y., Braun, P., Monetti, R., Bunde, A., and Havlin S.: Nonlinear volatility of river flux flunctuations, Phys. Rev. (E), 67, 042101, 1-4, 2003.

Murrone, F., Rossi, F., and Claps, P.: Conceptually-based shot noise modeling of streamflows at short time intervals, Stoch. Hydrol. Hydrauli., 11, 483-510, 1997.

Nicolis, C. and Nicolis, C. G.: Is there a Climatic Attractor?, Nature, 311, 529-532, 1984.

Osborne, A. R. and Provenzale, A.: Finite correlation dimension for stochastic systems with power-law spectra, Physica D, 35, 357-381, 1989.

Packard, N. H., Crutchfield, J. P., Farmer, J. D., and Shaw, R. S.: Geometry from a time series, Phys. Rev. Lett., 45, 712-716, 1980.

Pasternack, G. B.: Does the river run wild? Assessing chaos in hydrologic systems, Adv. Wat. Resour., 23, 253-260, 1999.

Peter, M. K., Jennifer, P. B., and Michael, C. F.: Climatic and hydrologic variability in a coastal watershed of southwestern British Columbia, JAWRA, 38, 1437-1449, 2002.

Piechota, T. C. and Dracup, J. A.: Long range streamflow forecasting using El Niño-Southern Oscillation Indicators, J. Hydrol. Engng., 4, 144-151, 1999.

Pikovsky, A.: Noise filtering in the discrete time dynamical systems, Sov. J. Commun. Technol. Electron., 31, 911-914, 1986.
Redmond, K. T. and Koch, R. W.: Surface climate and streamflow variability in the western United States and their relationship to large-scale circulation indices, Water Resour. Res., 27, 23812399, 1991.

Regonda, S., Sivakumar, B., and Jain, A.: Temporal scaling in river flow: Can it be chaotic?, Hydrol. Sci. J., 49, 373-385, 2004.

Rodriguez-Iturbe, I., De Power, B. F., Sharifi, M. B., and Georgakakos, P. K.: Chaos in rainfall, Water Resour. Res., 25, 16671675, 1989.

Schertzer, D., Tchiguirinskaia, I., Lovejoy, S., Hubert, P., Bendjoudi, H., and Larcheveque, M.: Discussion of "Evidence of chaos in the rainfall-runoff process", Which chaos in the rainfallrunoff process? Hydrol. Sci. J., 47, 139-147, 2002.

Schreiber, T. and Schmitz, A.: Improved surrogate data for nonlinearity tests, Phys. Rev. Lett., 77, 635-638, 1996.

Schreiber, T. and Schmitz, A.: Surrogate time series, Physica D, 142, 346-382, 2000.

Sivakumar, B., Liong, S. Y., Liaw, C. Y., and Phoon, K. K.: Singapore Rainfall Behavior: Chaotic?, J. Hydrol. Engng., 4, 38-48, 1999.

Sivakumar, B.: Rainfall dynamics at different temporal scales: A chaotic perspective, Hydrol. Earth Sys. Sci., 5, 1-7, 2001, SRef-ID: 1607-7938/hess/2001-5-1.

Sivakumar, B., Jayawardena, A. W.: An investigation of the presence of low-dimensional chaotic behavior in the sediment transport phenomenon, Hydrol. Sci. J., 47, 405-416, 2002.

Takens, F.: Detecting strange attractors in turbulence, in: Lecture Notes in Mathematics, edited by: Young, L. S., Springer, Berlin, 1981.

Theiler, J.: Spurious dimension from correlation algorithms applied to limited time-series data, Phys. Rev. (A), 34, 2427-2432, 1986.

Theiler, J. and Prichard, D.: Using "Surrogate Surrogate Data" to calibrate the actual rate of false positives in tests for nonlinearity in time series, Fields Institute Communications, 11, 99-113, 1996.

Tong, H.: Nonlinear Time Series, A Dynamic System Approach, Oxford University Press, Oxford, 1990.

Weiss, G.: Shot noise models for the generation of synthetic streamflow data, Water Resour. Res., 13, 101-108, 1977. 